Article

\title{
Spray-Dried Formulations Rich in Malvidin from Tintorera Grape Wastes: Characterization, Stability, and Storage
}

\author{
María Dolores López-Belchí ${ }^{1, *(\mathbb{D})}$, Esteban F. Caamaño ${ }^{2}$, Guillermo Pascual $^{1}\left(\mathbb{D}\right.$, Felipe Noriega $^{1}$ (D), \\ Paulo Fierro-Morales ${ }^{1}$, María Eugenia Romero-Román ${ }^{1}$ (D), Pamela Jara ${ }^{1}$, Mauricio Schoebitz ${ }^{3}$ (D), Ignacio Serra ${ }^{1}$ \\ and Diego A. Moreno $4, *$ (D)
}

1 Department of Plant Production, Faculty of Agronomy, University of Concepcion, Avenida Vicente Mendez, 595, Chillán 3812120, Chile; gpascual@udec.cl (G.P.); fnoriega@udec.cl (F.N.); pfierro@udec.cl (P.F.-M.); mariaeugeromero@udec.cl (M.E.R.-R.); pamejaraz@udec.cl (P.J.); iserra@udec.cl (I.S.)

2 Endocrinology and Immunology Laboratory, Department of Biological Science, Universidad Andrés Bello, Santiago 7550196, Chile; e.caamaomolina@uandresbello.edu

3 Department of Soil Science and Natural Resources, Faculty of Agronomy, University of Concepcion, P.O. Box 160 C, Concepcion 4070386, Chile; mschoebitz@udec.cl

4 Phytochemistry and Healthy Foods Lab., Food Science and Technology Department, CEBAS-CSIC, Campus Universitario de Espinardo, Edificio 25, E-30100 Espinardo, Spain

* Correspondence: mlopezb@udec.cl (M.D.L.-B.); dmoreno@cebas.csic.es (D.A.M.)

Citation: López-Belchí, M.D.; Caamaño, E.F.; Pascual, G.; Noriega, F.; Fierro-Morales, P.; Romero-Román, M.E.; Jara, P.; Schoebitz, M.; Serra, I.; Moreno, D.A. Spray-Dried

Formulations Rich in Malvidin from Tintorera Grape Wastes:

Characterization, Stability, and Storage. Processes 2021, 9, 518. https://doi.org/10.3390/pr9030518

Academic Editor: Raquel Rodríguez Solana

Received: 16 February 2021

Accepted: 8 March 2021

Published: 12 March 2021

Publisher's Note: MDPI stays neutral with regard to jurisdictional claims in published maps and institutional affiliations.

Copyright: (C) 2021 by the authors Licensee MDPI, Basel, Switzerland. This article is an open access article distributed under the terms and conditions of the Creative Commons Attribution (CC BY) license (https:/ / creativecommons.org/licenses/by/ $4.0 /)$.

\begin{abstract}
This research was focused on developing means of Tintorera grape (Vitis vinifera L.) waste recovery, devising new value-added uses for that material and optimizing of anthocyanin-rich formulations by spray-drying in order to obtain novel ingredients, all for food industry use. First, the identification of phenolic compounds in Tintorera grape extracts by HPLC-DAD-ESI-MS ${ }^{\mathrm{n}}$ enabled characterization of the raw material's health-promoting characteristics. Maintaining the spray-dried products for 4 weeks' storage enabled study of the formulation's loss of anthocyanins and antioxidant properties due to drying process temperatures as well as analysis of the retention and stability of such compounds under different conditions $\left(20\right.$ and $\left.40^{\circ} \mathrm{C}\right)$. Tintorera grapes presented a significant amount of Malvidin 3-O-hex (5.66 $\left.\mathrm{mg} \mathrm{g}^{-1} \mathrm{DW}\right)$. Anthocyanins in spray-dried formulations were stable for 4 weeks. Optimal conditions in the spray-dryer facilitated the products' antioxidant capacity; for instance, using $10 \%$ maltodextrin (w:v) at $90{ }^{\circ} \mathrm{C}$ inlet temperature had a little influence on the reduction in encapsulated malvidin 3-O-hex (15\%) and presented $3.35 \mathrm{mg} \mathrm{GAE} \mathrm{g}^{-1} \mathrm{DW}$ of total polyphenol contents, $98.62 \mu \mathrm{mol}$ Trolox (FRAP assay), and $39.97 \mu \mathrm{mol}$ Trolox (DPPH assay). Principal component analyses (PCA) showed a high degree of dependence between anthocyanin content and maintenance of antioxidant capacity during storage. These results offer a promising alternative for the industrial management of wine-making wastes in order to implement a sustainable protocol for development of Tintorera grape extracts rich in bioactive compounds for new beverages and functional foods.
\end{abstract}

Keywords: anthocyanin; novel grape ingredients; Garnacha Tintorera; waste management; food waste recovery

\section{Introduction}

The phenolic compounds in plant-derived foods have been associated with potential health-promoting characteristics due to their ability to act as antioxidants and free-radical scavengers [1]. Most plant phenolic compounds appear as simple phenols and flavonoids, which are polar hydroxylated or glycosylated compounds of relatively low molecular weights. Other plant polyphenols are mostly high molecular polymers such as condensed tannins and proanthocyanidins, which are categorized as non-extractable polyphenols. The abovementioned compounds can be found in grape wastes [2]. Among grapes, Vitis vinifera is the world's largest fruit crop and it generates a large number of wastes that must be 
treated adequately to avoid contaminating the areas of production and elaboration of wine [3]. The nature of the wastes produced depends closely on the raw materials (e.g., the grape cultivar), vinification procedures and conditions [3]. The wastes are consumed as table grapes or processed into raisins, juices, jams, or other products [4]. The Tintorera grape (Vitis vinifera L.) is a grape cultivar with a red-colored berry flesh, is a Teinturier cultivar used as color enhancer in high-quality red wines, and is cultivated worldwide for this purpose [5]. In addition, Tintorera varieties typically contain monoglycosylated anthocyanins, being malvidin 3-glucoside the most common [5]. On the other hand, quercetin 3-O-glucoside and quercetin 3-O-glucuronide are the predominant compounds in the flavonol glycoside profile of most grapes [6,7]. Therefore, Tintorera grape by-products can be used for valorization as sources of functional ingredients rich in bioactive phytochemicals [8]. In fact, using such agrowastes to develop new ingredients is a potentially profitable means of reducing their negative environmental impact [3]. Spray-drying is a technique that provides protection and stability to key bioactive compounds which also masks off-flavors by providing a physical barrier [9]. The main advantage found in spray-drying compared to freeze-drying is that this process is more suitable for industrial scale-up and taking into account the large volumes of grape wastes produced by agri-food industry, the management is more handle facing spray-drying process than freeze-drying. In addition, the production time of formulations is an advantage since spray-drying is a process faster than freeze-drying. However, in spray-drying, atomization process influences the size of the droplets formed and therefore the heat-transferring surface between the dry air and the liquid feed. Though highly protective and thus widely employed in the food industry, the process of spray-drying can provoke significant loss of bioactive compounds. Therefore, feed, inlet air, and outlet air temperatures must be optimized during the process, i.e., the liquid feed temperature affects its viscosity and thus its homogeneous spraying capacity, the inlet air temperature is directly proportional to the drying rate and final water content, and the outlet temperature is effectively the control index of the dryer. However, atomization is dependent on additional parameters; geometric aspects of the nozzle, the air:solution volume ratio, and temperature control all have effects on the physical state of the final product [10]. Several authors were able to determine that the different conditions used for spray-drying would protect the Vitis vinifera polyphenols from degradation, mainly oxidation of the bioactive compounds due to oxygen from the environment when these were formulated under correct storage conditions [11]. Some examples of ingredients used to protect the bioactive compounds in Vitis vinifera products (e.g., alginate) previously had been reported [2]. Moreno et al. [12] using different wall materials but maintaining a constant temperature of $25^{\circ} \mathrm{C}$, developed models to explain the degradation of Vitis vinifera polyphenolic compounds (which also had been studied in Vitis labrusca using spray-drying), but that study focused on antimicrobial protection [13]. Thus, the idea of encapsulating phenolic compounds from berries and grapes and their by-products is not new. However, until now, there had been no such studies of agrowastes of Tintorera grapes, a cultivar with high antioxidant capacity, and very rich in anthocyanins which is affected by both the temperature of the process as well as that during storage. Thus, this research focused on evaluating the waste produced by the wine industry related to overproduction of Tintorera grape and transforming that biomass into a source of valuable functional ingredients with great potential for health-promoting biological activities. Moreover, the goal was to provide new knowledge about the composition and operational protocols necessary to obtain the new formulations in order to deliver novel and innovative products derived from Tintorera grape wastes, once recovered and valorized as a source of functional ingredients for industrial applications.

\section{Materials and Methods}

\subsection{Chemicals}

The compounds 2,2-diphenyl-1-picrylhydrazyl radical (DPPH), Folin-Ciocalteu reagent, monobasic sodium phosphate, and dibasic sodium phosphate were obtained from Sigma-Aldrich 
(MilliporeSigma, St. Louis, MO, USA). Meanwhile, 6-hydroxy-2,5,7,8-tetramethylchroman-2carboxylic acid (Trolox) was purchased from Fluka Chemika (Fluka, Neu-Ulm, Switzerland). Ultrapure water was produced using a Millipore water purification system. Formic acid, $\mathrm{FeCl}_{3}-6 \mathrm{H}_{2} \mathrm{O}$, TPTZ and acetate buffer was purchased from Merck (MilliporeSigma, Darmstadt, Germany). Besides, cyanidin 3-glucoside, delphinidin 3-galactoside, malvidin 3-galactoside, chlorogenic acid, rutin trihydrate, quercetin dihydrate, and maltodextrin DE-10 as carrier agents were obtained from Sigma-Aldrich Chemical Co. (MilliporeSigma, St. Louis, MO, USA). For the enzymatic assays, E. electricus AChE, acetylthiocholine iodide (ATCh), 5,5'-dithio-bis(2-nitrobenzoic) acid (DTNB), $\alpha$-glucosidase, PNP-G, and lipase were all supplied by Sigma-Aldrich Chemical Co. (MilliporeSigma, St. Louis, MO, USA).

\subsection{Material Collection}

Tintorera grapes were obtained from San Nicolás, Chile $\left(36.49^{\circ} \mathrm{S}, 72.20^{\circ} \mathrm{W}\right)$ during two consecutive seasons (2018 and 2019) to carry out a replication of the design of the experiment. After harvesting, all samples were stored at $-80{ }^{\circ} \mathrm{C}$ until processing and analysis.

\subsection{Sample Preparation and Spray-Drying of Tintorera Grape Extracts}

An aqueous extract of Tintorera was mixed with $50 \mathrm{~mL}$ of maltodextrin $(10 \%$ and $30 \%)$ and stirred at $300 \mathrm{rpm}$ for $2 \mathrm{~h}$. The powder was obtained by means of a spray-drying using a Mini Spray Dryer-B290 (BÜCHI, Flawil, Switzerland). The mixture was fed into the spray-dryer at room temperature with a flow rate of $4 \mathrm{~mL} \mathrm{~min}^{-1}$. The inlet temperatures were maintained at 90 and $120^{\circ} \mathrm{C}$, whereas outlet air temperatures were 50 and $80{ }^{\circ} \mathrm{C}$, respectively. The dried powder was collected and stored in an opaque, air-tight container at $4{ }^{\circ} \mathrm{C}$ for further analysis. Four treatments were carried out LT10 (10\% maltodextrin and inlet temperature at $\left.90^{\circ} \mathrm{C}\right)$, LT30 $\left(30 \%\right.$ maltodextrin and inlet temperature at $\left.90{ }^{\circ} \mathrm{C}\right), \mathrm{HT} 10$ $\left(10 \%\right.$ maltodextrin and inlet temperature at $\left.120{ }^{\circ} \mathrm{C}\right)$, and HT30 $(30 \%$ maltodextrin and inlet temperature at $120^{\circ} \mathrm{C}$ ). The microspheres obtained in the four treatments (LT10, LT30, HT10, and HT30) were kept in controlled chambers (with controlled relative humidity at $60 \%$ ) at 20 and $40^{\circ} \mathrm{C}$, and the anthocyanin concentration changes of the encapsulated along one month were studied.

\subsection{Identification of Phenolic Compounds of Tintorera Grape Wastes and the New Formulations by HPLC-DAD-ESI-MS ${ }^{n}$ and Quantification by HPLC-DAD}

Raw materials and formulations were mixed with 5 volumes of methanol/formic acid/water (25:1:24) for the extraction of anthocyanins, mainly malvidin 3-hexoside and other phenolic compounds, following the protocol described by [14]. Shortly, a Luna C18 column ( $250 \mathrm{~mm} \times 4.6 \mathrm{~mm}, 5 \mathrm{~mm}$ particle size; Phenomenex, Macclesfield, UK) and $1 \%$ formic acid and acetonitrile were used as the mobile phases A and B, respectively, with a flow rate of $1 \mathrm{~mL} \mathrm{~min}^{-1}$. The HPLC-DAD-ESI-MS ${ }^{\mathrm{n}}$ analyses were carried out using an Agilent HPLC 1200 system (Agilent Technologies, Waldbronn, Germany) and coupled to a mass detector in series. The ionization conditions were $350{ }^{\circ} \mathrm{C}$ and $4 \mathrm{kV}$, for capillary temperature and voltage, respectively. The nebulizer pressure and nitrogen flow rate were $65.0 \mathrm{psi}$ and $11 \mathrm{~L} \mathrm{~min}^{-1}$, respectively. The full-scan mass covered the range of $m / z$ from 100 to 1200 . The mass spectrometry data were acquired in the positive ionization mode for anthocyanins and in the negative ionization mode for other flavonoids and phenolic acids. For the quantification, an Agilent HPLC-DAD 1100 system (Agilent Technologies, Waldbronn, Germany) was employed, consisting of a multisolvent delivery system (G1312A), an in-line degasser (G1322A), an autosampler (G1313A) and a photodiode array detector (G1315B). Chromatograms were recorded at 280, 320, 360, and $520 \mathrm{~nm}$, and required standards were used. 


\subsection{Biological Activity In Vitro of Tintorera Grapes: Acetylcholinesterase Activity Assay, Pancreatic Lipase Activity Assay, and $\alpha$-Glucosidase Activity Assay}

Enzymatic assays were conducted in order to study the biological potential of Tintorera grape extracts. Enzymatic assays of acetylcholinesterase (AChE) and $\alpha$-Glucosidase activity assay were performed using the methodology described by Noriega et al. [15], whereas lipase activity assay was modified from the previous report by Gilham et al. [16]. For the assays of acetylcholinesterase (AChE), we modified the Ellman method [17] where different concentrations of acetylthiocholine (ATCh) were prepared from a freshly distilled water $(1,0.5,0.2$, and $0.1 \mathrm{mM})$. The inhibition reaction was done with $100 \mu \mathrm{L}$ of Vitis vinifera L. extracts and dilutions. The spectrophotometric study was incubated at $37^{\circ} \mathrm{C}$ for $15 \mathrm{~min}$ and the absorbance was measured by a Thermo Scientific UV-Vis Orion AquaMate 8000 spectrophotometer (Madrid, Spain) at $412 \mathrm{~nm}$. The measurement of enzymatic activity for pancreatic lipase was carried out using 4-nitrophenyl dodecanoate as substrate. The inhibition reaction was done with $100 \mu \mathrm{L}$ of Vitis vinifera extract and dilutions. The spectrophotometric measures were incubated at $37^{\circ} \mathrm{C}$ for $10 \mathrm{~min}$ and the absorbance was measured by a Thermo Scientific UV-Vis Orion AquaMate 8000 spectrophotometer (Madrid, Spain) at $400 \mathrm{~nm}$. Finally, inhibitory activity of $\alpha$-glucosidase was determined by modification of a previously reported method [18]. Moreover, 4-nitrofenil $\alpha$-D-glucopiranosido (PNP-G) was used as substrate and chromogenic reagent at concentration of $1,0.5$, and $0.2 \mathrm{mM}$ prepared from a freshly distilled water. The inhibition reaction was done with Vitis vinifera $\mathrm{L}$. extracts and dilutions. The spectrophotometric analyses were incubated at $30^{\circ} \mathrm{C}$ for $15 \mathrm{~min}$ and the absorbance was measured by a Thermo Scientific UV-Vis Orion AquaMate 8000 spectrophotometer (Madrid, Spain) at $400 \mathrm{~nm}$. In all enzymatic assays, a phosphate buffer solution was used as blank and was tested with a mixture of methanol, formic acid, and distilled water (25:1:24). Six replications were performed for each enzymatic assay.

\subsection{Total Polyphenol Content and Antioxidant Capacity of Tintorera Grapes and Formulations}

The aforementioned hydroalcoholic extracts were prepared to analyze total polyphenol content and antioxidant capacity of formulations of Tintorera grapes. In short, raw materials and formulations were mixed with 5 volumes of methanol/formic acid/water (25:1:24) for the extraction of phenolic compounds. Total phenolic content (TP) was determined by the Folin-Ciocalteu reagent method [19]. The samples were prepared by adding $750 \mu \mathrm{L}$ of Folin-Ciocalteu $1 \mathrm{~N}$ reagent, $750 \mu \mathrm{L}$ of $20 \%$ sodium carbonate, and $500 \mu \mathrm{L}$ of the Tintorera grape extracts and powders. All of them were maintained for $2 \mathrm{~h}$ in the dark and absorbance was measured through a Thermo Scientific UV-Vis Orion AquaMate 8000 spectrophotometer (Madrid, Spain). Results were expressed as milligrams of gallic acid equivalents per grams (mg GAE $\mathrm{g}^{-1} \mathrm{DW}$ ). Free-radical scavenging activities were determined using the DPPH method according to Mena et al. [20]. Briefly, the antioxidant activity was evaluated by measuring the variation in absorbance at $515 \mathrm{~nm}$ after $30 \mathrm{~min}$ of reaction with the radical (for DPPH) and FRAP assay (ferric reducing antioxidant power assay) using $30 \mu \mathrm{L}$ of the extract (per sample), $300 \mu \mathrm{L}$ of distilled water, and the addition of $3000 \mu \mathrm{L}$ of FRAP reagent $\left(\mathrm{FeCl}_{3}-6 \mathrm{H}_{2} \mathrm{O} 20 \mathrm{mM}\right.$, TPTZ $10 \mathrm{mM}$, and acetate buffer $\left.0.3 \mathrm{mM}\right)$ incubated at $37^{\circ} \mathrm{C}$ for $30 \mathrm{~min}$. The assays were performed using Thermo Scientific UV-Vis Orion AquaMate 8000 spectrophotometer (Madrid, Spain). The results were expressed as micromole Trolox $\mathrm{mg}^{-1}$ dry weight. Six replications were carried out per sample.

\subsection{Scanning Electron Microscopy of Formulations}

Powder samples were attached to double-sided adhesive tape mounted on SEM stubs, covered with gold layer $(9 \mathrm{~nm})$ under vacuum and observed in scanning electronic microscope (FEI-Inspect S50) working at $5 \mathrm{kV}$, with 10,003 and 50,003 of magnification. 


\subsection{Statistical Analysis}

Phenolic compounds, antioxidant capacity, and spray-drying assay were studied by using one-way analysis of variance (ANOVA), with a completely random design $(n=4)$, and Tukey test at a level of significance $p<0.05$. The results of biological activity are presented as descriptive statistics expressed as the mean and standard deviation (2 consecutive years), whereas the inhibition enzyme assays were calculated using the GraphPad Prism v. 6.1 software (GraphPad Prism ${ }^{\circledR}$ software, Inc., San Diego, CA, USA). Finally, Biplot associated with principal components analyses (PCA) was obtained by mean centered data based on the eigen values to determine the correlations among variables, the discrimination of anthocyanin contents of Vitis vinifera and the antioxidants properties, and loss of malvidin 3-hexoside at different process and storage temperatures. All analyses were performed using the InfoStat v. 2017 software.

\section{Results and Discussion}

\subsection{Identification and Quantification of Phenolic Compounds in Tintorera Grapes}

The analyses of phenolic compounds in Tintorera grape were carried out by HPLCDAD-ESI $/ \mathrm{MS}^{\mathrm{n}}$ using the whole grape without separating seeds and flesh, in order to avoid oxidation. Acidified hydromethanolic extracts were prepared for enhancing the extraction of anthocyanins. Eighteen different compounds were identified in the samples, where the major components were the anthocyanins (16 out of 18 detected compounds). A detailed tentative assignment of the anthocyanin peaks identities is shown in Table 1.

Table 1. Identification and quantification $\left(\mathrm{mg} \mathrm{g}^{-1} \mathrm{DW}\right)$ of phenolic compounds in Tintorera grape (Vitis vinifera L.) by HPLC-Diode Array Detector (DAD)-Electro spray ionization (ESI)/ $\mathrm{MS}^{\mathrm{n}}$.

\begin{tabular}{|c|c|c|c|c|c|c|c|}
\hline Peak & RT (min) & $\lambda \max (\mathrm{nm})$ & $\mathbf{M}^{+}$or $\mathbf{M}^{-}$ & Ion & MSn & Compound & Total Concentration \\
\hline 1 & 22.3 & 278,520 & 465 & + & 303 & Delphinidin 3-O-hexoside & $0.82 \pm 0.002$ \\
\hline 2 & 24.7 & 280,516 & 449 & + & 287 & Cyanidin 3-O-hexoside & $0.57 \pm 0.006$ \\
\hline 3 & 26.5 & 276,524 & 479 & + & 317 & Petunidin 3-O-hexoside & $1.02 \pm 0.001$ \\
\hline 4 & 28.1 & 358 & 481 & - & 316 & Myricetin 3-O-glucoside & $0.22 \pm 0.004$ \\
\hline 5 & 28.3 & 278,514 & 463 & + & 301 & Peonidin 3-O-hexoside & $3.40 \pm 0.016$ \\
\hline 6 & 29.6 & 276,522 & 493 & + & 331 & Malvidin 3-O-hexoside & $5.66 \pm 0.122$ \\
\hline 7 & 33.2 & $282,346,524$ & 507 & + & 303 & Delphinidin 3-O-(6-acetyl)-glycoside & $0.33 \pm 0.002$ \\
\hline 8 & 36.0 & 354 & 477 & - & 301 & Quercetin 3-O-glycoside & $0.67 \pm 0.003$ \\
\hline 9 & 36.9 & 278,520 & 491 & + & 287 & Cyanidin 3-O-(6-acetyl)-glycoside & $0.23 \pm 0.001$ \\
\hline 10 & 38.7 & 276,528 & 521 & + & 317 & Petunidin 3-O-(6-acetyl)-glycoside & $0.41 \pm 0.005$ \\
\hline 11 & 40.8 & 278,526 & 505 & + & 301 & Peonidin 3-O-(6-acetyl)-glycoside & $0.78 \pm 0.008$ \\
\hline 12 & 42.9 & 280,528 & 535 & + & 331 & Malvidin 3-O-(6-acetyl)-glucoside & $1.25 \pm 0.005$ \\
\hline 13 & 46.6 & 280,532 & 611 & + & 303 & Delphinidin 3,5-O-di-hexoside & $0.21 \pm 0.107$ \\
\hline 14 & 49.4 & 280,522 & 625 & + & 301 & Peonidin 3,5-O-diglucoside & $0.15 \pm 0.011$ \\
\hline 15 & 51.1 & 278,528 & 655 & + & 331 & Malvidin 3,5-O-di-hexoside & $0.15 \pm 0.002$ \\
\hline 16 & 53.0 & 280,536 & 625 & + & 317 & Petunidin 3,5-O-di-hexoside & $0.13 \pm 0.001$ \\
\hline 17 & 57.7 & 280,518 & 609 & + & 301 & Peonidin 3,5-O-diglucoside & $0.28 \pm 0.004$ \\
\hline 18 & 58.9 & 280,532 & 639 & + & 331 & Malvidin derivative & $1.65 \pm 0.052$ \\
\hline
\end{tabular}

The major representative of the phenolic compounds in the Tintorera grape was the malvidin 3-hexoside. Peonidin 3,7-O-diglucoside was also identified, as previously found by [5], since 2 clear productions were generated from $m / z 625(\mathrm{~m} / z 463$ and 301), although it was not quantified. Anthocyanins 3,7-diglucosides and 3,5-diglucosides have been described in other plants and their structures have been unequivocally elucidated by ${ }^{1} \mathrm{H}$ NMR data [21]. Peaks 1, 2, 3, 5, and 6 presented derivatives of the 3-glucosides of the anthocyanidins delphinidin, cyanidin, petunidin, peonidin, and malvidin, respectively. Other anthocyanin derivatives were identified as well, delphinidin 3-O-(6-acetyl)-glucoside (peak 7, $m / z$ 507, 303 and 204), cyanidin 3-O-(6-acetyl)-glucoside (peak 9, $m / z$ 491, 287 and 204), petunidin 3-O-(6-acetyl)-glucoside (peak 10, $\mathrm{m} / \mathrm{z}$ 521, 317 and 204), and peonidin 3-O(6-acetyl)-glucoside (peak 11, m/z 505, 301 and 204). These compounds are common to the $V$. vinifera cultivars, and they were easily identified by their absorbance spectra as well as the mass fragments information [5]. Besides, peaks 14, 15, and 16, represented derivatives 
of the 3,5-O-diglucosides, peonidin 3,5-O-di-glucoside, malvidin 3,5-O-di-hexoside, and petunidin 3,5-O-di-hexoside. Some other derivatives of the peonidin and malvidin were also detected, though they were only identified by their anthocyanidin. Some additional flavonol glycosides were also detected, and normally, the presence of these compounds may cause interference in the separation and identification [6]. The peaks 4 and 8 were confirmed by comparison of the retention times together with their absorbance and mass spectral information. Myricetin 3-O-glucoside $(\mathrm{m} / \mathrm{z} 316)$, quercetin 3-O-glucoside $(\mathrm{m} / \mathrm{z}$ $301)$, isorhamnetin 3-O-glucoside $(\mathrm{m} / \mathrm{z} 315)$, and syringetin 3-O-glucoside $(\mathrm{m} / \mathrm{z} 345)$ were identified (although not all were quantified), also in accordance to previous findings about the flavonol glycosides composition of $V$. Vinifera red cultivars [6,22]. Other authors found values lower for quercetin 3-O-glucoside ranged from 0.0014 to $0.0335 \mathrm{mg} \mathrm{g}^{-1}$, whereas for isorhamnetin 3-glucoside and syringetin 3-O-glucoside values ranged from 0.0016 to $0.0035 \mathrm{mg} \mathrm{g}^{-1}$ [22] though they were not detected in this experiment. Table 1 also shows the total phenolics content ( $\left.\mathrm{mg} \mathrm{g}^{-1} \mathrm{DW}\right)$ in Tintorera grape as well, separated by anthocyanins, flavonols, and hydroxycinnamic acid derivatives. In Tintorera grape, total anthocyanin content was high $\left(17.04 \mathrm{mg} \mathrm{g}^{-1}\right)$. Other researchers found values of malvidin 3-O-glucoside around $0.797 \mathrm{mg} \mathrm{g}^{-1}$, malvidin 3-O-6-coumaryl-glucoside around $0.119 \mathrm{mg} \mathrm{g}^{-1}$, and peonidin 3-O-glucoside around $0.614 \mathrm{mg} \mathrm{g}^{-1}$ during raisining process at initial time [23]. These contents of anthocyanins were lower than indicated in our study. In addition, comparison with specifically Tintorera grapes in other manuscript turned out to be difficult because in other works, authors only reported the wine contents [23,24]. In the studied samples, 16 anthocyanins were quantified, being malvidin 3-O-hexoside the major compound detected (5.66 $\left.\mathrm{mg} \mathrm{g}^{-1}\right)$, followed by peonidin 3-O-hexoside $\left(3.40 \mathrm{mg} \mathrm{g}^{-1}\right)$. The total flavonols quantified in Tintorera grapes was $0.89 \mathrm{mg} \mathrm{g}^{-1}$, considering only 2 major flavonols detected, the quercetin 3-glucoside $\left(0.67 \mathrm{mg} \mathrm{g}^{-1}\right)$ and the myricetin 3-O-glucoside $\left(0.22 \mathrm{mg} \mathrm{g}^{-1}\right)$. This could be due to the difficulty to analyze minor components stored in external areas of cellular vacuoles and therefore being more sensitive to oxidation and degradation [25]. To observe the effect of temperature, process, and maltodextrin (LT10, LT30, HT10, and HT30) on polyphenols compounds from Tintorera grapes, a Supplementary Materials data have been included, where it can be observed that spray-drying process carried out with $10 \%$ maltodextrin and temperature of $90{ }^{\circ} \mathrm{C}$ produced lower loss of the content of the main polyphenolic compounds.

\subsection{Biological Activity of Tintorera Grapes In Vitro}

Table 2 shows the enzymatic inhibition of acetylcholinesterase, lipase, and $\alpha$-glucosidase enzyme activities by the Tintorera grape extracts.

Table 2. Inhibitory activity of Tintorera grape $\left(\mathrm{mg} \mathrm{mL}^{-1}\right)$ extract on acetylcholinesterase, lipase, and $\alpha$-glucosidase enzymes ${ }^{\text {a }}$.

\begin{tabular}{cc}
\hline Enzyme & IC $_{\mathbf{5 0}}$ \\
\hline Acetylcholinesterase & $0.29 \pm 0.02$ \\
Lipase & $0.16 \pm 0.07$ \\
$\alpha$-glucosidase & $0.26 \pm 0.02$ \\
\hline
\end{tabular}

a Data correspond to means $(n=6)$.

The inhibition of the three enzymes by Tintorera extracts was high, highlighting its activity against acetylcholinesterase and $\alpha$-glucosidase. Regarding to lipase inhibition, the $\mathrm{IC}_{50}$ of the Tintorera grape extracts was slightly higher than some phenolic standards used in this assay $\left(0.14 \mathrm{mg} \mathrm{mL}^{-1}\right.$ for chlorogenic acid, $0.13 \mathrm{mg} \mathrm{mL}^{-1}$ for delphinidin 3-galactoside, and $0.13 \mathrm{mg} \mathrm{mL}^{-1}$ for kuromanin chloride), with the exception of malvidin 3-galactoside, which presented a similar dose $\left(0.16 \mathrm{mg} \mathrm{mL}^{-1}\right)$. In fact, it is necessary to emphasize that the $\mathrm{IC}_{50}$ values for common inhibitors such as orlistat was $0.123 \mathrm{mg} \mathrm{mL}^{-1}$ [26], a value close to what we have obtained with $0.16 \mathrm{mg} / \mathrm{mL}$, demonstrating a good inhibitory capacity of the Tintorera grape extract. 
In relation to $\mathrm{AChE}$ enzyme, in previous works, the $\mathrm{IC}_{50}$ values $\mathrm{AChE}$ inhibitory drugs were established as follows: physostigmine $1.8 \times 10^{-4} \mu \mathrm{g} \mathrm{mL} \mathrm{m}^{-1}$, rivastigmine $1.1 \times 10^{-3} \mu \mathrm{g} \mathrm{mL}^{-1}$, donepezil $2.5 \times 10^{-3} \mu \mathrm{g} \mathrm{mL}^{-1}$, and tacrine $1.5 \times 10^{-3} \mu \mathrm{g} \mathrm{mL}^{-1}$ [27]. The activity (low $\mathrm{IC}_{50}$ ) of pure compounds and drugs is usually much higher than the activity of the natural extract, however, although the extracts showed less inhibitory activity than that found in these drugs, it must be remembered that they have other advantages. These extracts do not usually have side effects. Therefore, at the concentrations obtained by us, they are still interesting as a dietary alternative.

On the other hand, the $\mathrm{IC}_{50}$ for anti-diabetic drugs, such as Amaryl (glimepiride) $\left(0.88 \mathrm{mg} \mathrm{mL}^{-1}\right)$, Betanorm (gliclazide) $\left(1.40 \mathrm{mg} \mathrm{mL}^{-1}\right)$, and Glucobay (acarbose) $\left(0.75 \mathrm{mg} \mathrm{mL}^{-1}\right)$ [28], were superior than results obtained from Tintorera grape extract, being, therefore, a good candidate for such purpose.

The inhibition kinetics (Figure 1) of the three enzymes was calculated to elucidate inhibition mode. As shown in Figure $1 \mathrm{a}-\mathrm{c}$, all inhibition kinetics curves crossed $\mathrm{X}$ axis, therefore, the inhibition type of Tintorera grapes for the three enzymes (acetylcholinesterase, lipase, and $\alpha$-glucosidase) was non-competitive. This situation indicates that phenolic compounds from Tintorera grapes have combined actions between inhibitor and enzyme as well as between inhibitor and enzyme-substrate complex. In addition, it is observed how blanks with buffer phosphate and control with a mixture of methanol, formic acid, and water (25:1:24) presented a lesser inhibition.
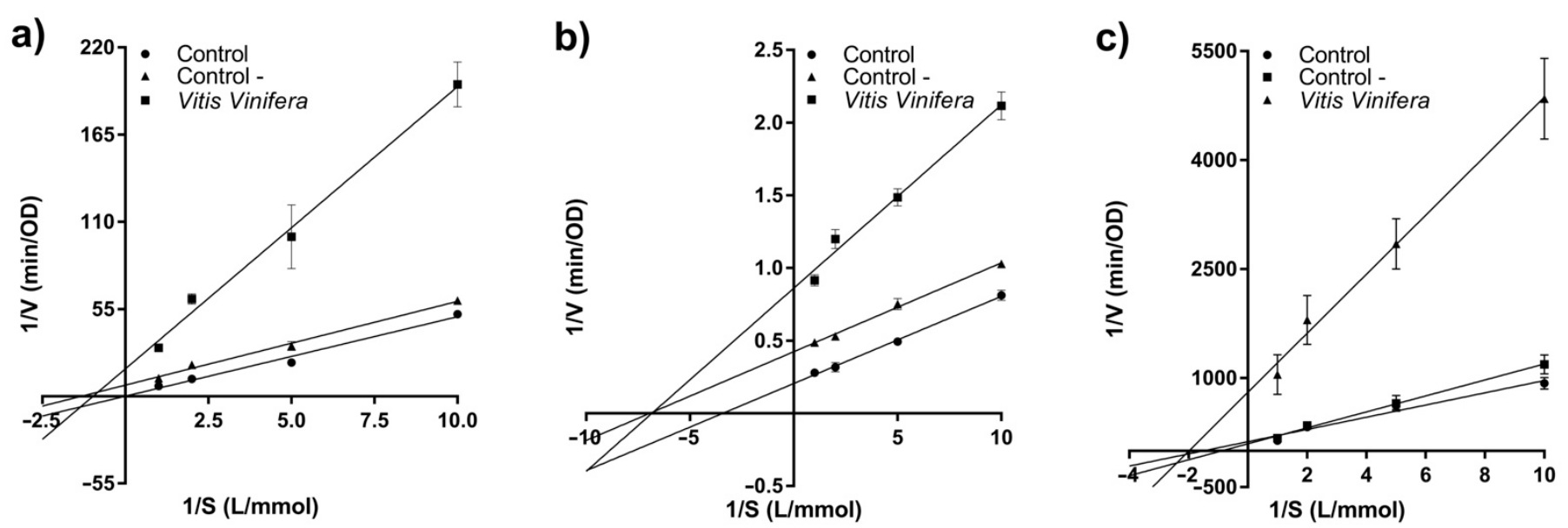

Figure 1. Lineweaver-Burk plot of extracts from Vitis vinifera on three enzymes. ((a) acetylcholinesterase, (b) lipase, and (c) $\alpha$-glucosidase).

Other authors have showed interest on biological activity of Vitis vinifera from its leaves, which are widely used in foods in countries such as Greece, Turkey, and Middle East area [29]. They evaluated the neuroprotective activity of leaf extracts by inhibition of acetylcholinesterase (AChE) using Ellman's method. Results revealed that Frankovka and Italian Riesling varieties presented the best $\mathrm{IC}_{50}$ values among all those studied, with values of $54.5 \pm 1.12$ and $62.8 \pm 1.54 \mu \mathrm{g} \mathrm{mL}^{-1}$, respectively, compared with galantamine, a drug widely used in the treatment of Alzheimer that expressed a value of $0.09 \pm 0.001 \mu \mathrm{g} \mathrm{mL}^{-1}$. These results reaffirm the importance of natural and inexpensive alternatives in the consumption of food rich in bioactive compounds as well as their use in pharmaceutical industry. Consequently, these results proved that Tintorera grape extracts are potent in vitro inhibitors of acetylcholinesterase, pancreatic lipase, and $\alpha$-glucosidase, so they may be developed-individually or in synergistic formulations-as natural alternatives for therapies and nutritional interventions. 


\subsection{Anthocyanins and Antioxidant Capacity in Spray-Drying Formulations of Tintorera Grape}

After analyzing the potential of the raw material and focusing on the manage waste produced by the overproduction of Tintorera grapes and their transformation into functional ingredients or beverage, strategies of drying were used.

Both, control treatment at $90{ }^{\circ} \mathrm{C}$ combined with $10 \%$ of maltodextrin (LT10) and treatment at $120{ }^{\circ} \mathrm{C}$ combined with $10 \%$ of maltodextrin (HT10) showed higher concentrations for all anthocyanins than the other treatments (Table 3).

Table 3. Main anthocyanin content $\left(\mathrm{mg} \mathrm{g}^{-1} \mathrm{DW}\right)$ in encapsulated Tintorera grape extracts.

\begin{tabular}{|c|c|c|c|c|}
\hline \multirow{2}{*}{ Treatments * } & \multicolumn{4}{|c|}{ Anthocyanin Content (mg g $\left.{ }^{-1} \mathrm{DW}\right)$} \\
\hline & Malvidin 3-O-Hexoside & Peonidin 3-O-Hexoside & Petunidin 3-O-Hexoside & Delphinidin 3-O-Hexoside \\
\hline LT10 & $0.90 \mathrm{~b}$ & $0.47 \mathrm{~b}$ & $0.19 b$ & $0.21 b$ \\
\hline LT30 & $0.51 \mathrm{c}$ & $0.25 c$ & $0.09 c$ & $0.09 c$ \\
\hline HT10 & $0.79 b$ & $0.34 b$ & $0.16 b$ & $0.18 b$ \\
\hline HT30 & $0.48 \mathrm{c}$ & $0.20 c$ & $0.08 \mathrm{c}$ & $0.12 \mathrm{c}$ \\
\hline Tintorera grapes & $5.66 \mathrm{a}$ & $3.40 \mathrm{a}$ & $1.02 \mathrm{a}$ & $0.82 \mathrm{a}$ \\
\hline
\end{tabular}

${ }^{*}$ LT10 are extracts of grapes encapsulated with $10 \%$ maltodextrin at $90{ }^{\circ} \mathrm{C}$, LT30 are extracts of grapes encapsulated with $30 \%$ maltodextrin at $90{ }^{\circ} \mathrm{C}$, HT10 are extracts of grapes encapsulated with $10 \%$ maltodextrin at $120^{\circ} \mathrm{C}$, and HT30 are extracts of grapes encapsulated with $30 \%$ maltodextrin at $120^{\circ} \mathrm{C}$. Different letters within the same column means significant differences at $p<0.05$ in spray-dried powders and Tintorera grape extracts according to Tukey test.

This greater retention of anthocyanins seems to be determined by the optimal percentage of the wall material. In the case of maltodextrin, $10 \%$ would be adequate since it is able to immobilize Tintorera extracts.

In Figure 2, formulations from spray drying (inlet air temperature of 90 and $120^{\circ} \mathrm{C}$ ) of Tintorera grapes with maltodextrin are presented. Treatments HT10 and HT30 (Figure 2c,d) showed spherical shape more piled up due to a strong Tintorera grape extract attraction with maltodextrin to each other. Even though, the shape of formulated powders and attraction between encapsulation agent (maltodextrin) and Tintorera extract were efficient due to temperature, anthocyanins content was affected by temperature conditions.

Antioxidant capacity, FRAP and DPPH assay, were carried out for Tintorera grape extracts and formulations by spray-drying (Table 4 ).

The values obtained for the grape extracts in the FRAP assay reached to $203.40 \mu \mathrm{mol}$ Trolox $\mathrm{g}^{-1}$ DW. If we compare these values of FRAP with those found by [14] in other fruits like maqui or açai, we observe that Tintorera grapes presented values as high as those, consequently, they seem to be a promising source of antioxidant compound. Respect to the $\mathrm{DPPH}^{*}$ assay, Tintorera grapes $\left(108.27 \mu \mathrm{mol}\right.$ Trolox $\left.\mathrm{g}^{-1} \mathrm{DW}\right)$ exhibited twice the activity of calafate berry ( $51.55 \mu \mathrm{mol}$ Trolox $\left.\mathrm{g}^{-1} \mathrm{DW}\right)$ [21]. These high values for Tintorera grapes are attributed to their remarkable anthocyanin content as tested in other fruits by several authors [30]. Another interesting aspect is that values of DPPH assay were highly correlated with the total polyphenol contents. This did not occur with the FRAP assay. Hence, this would indicate that the polyphenols obtained in Tintorera extracts could be better free radical scavengers than reducers. This is easily observable in biplot associated with principal component analyses (see below in Figure 3). Total polyphenol contents and antioxidant capacity in formulations were lesser than Tintorera grapes due to the losses of anthocyanins and other phenolic compounds. Even though, the treatments LT10 and HT10 presented optimal results. Anthocyanins application in human health is limited to liquid. Nevertheless, liquid formulation is affected by external factors such as light exposure, humidity, the presence of oxygen, and temperature [31]. For that reason, spray drying is a suitable method to formulate and conserve bioactive compounds over time. Above all, in order to take advantage of an overproduction of Tintorera grapes with high antioxidant properties and biological activity. 


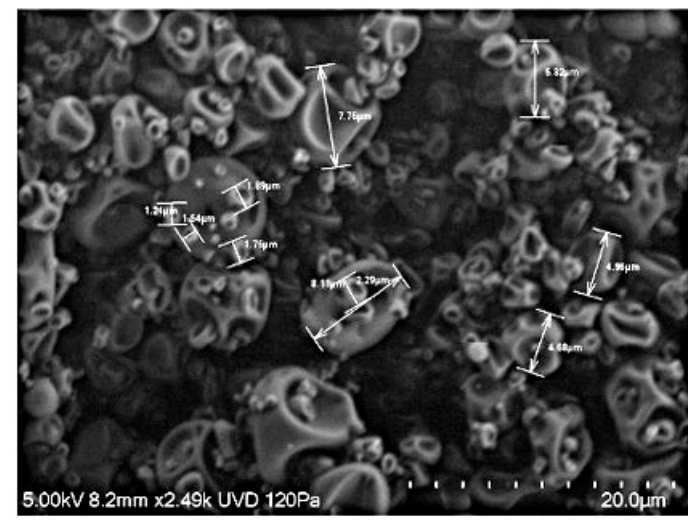

a

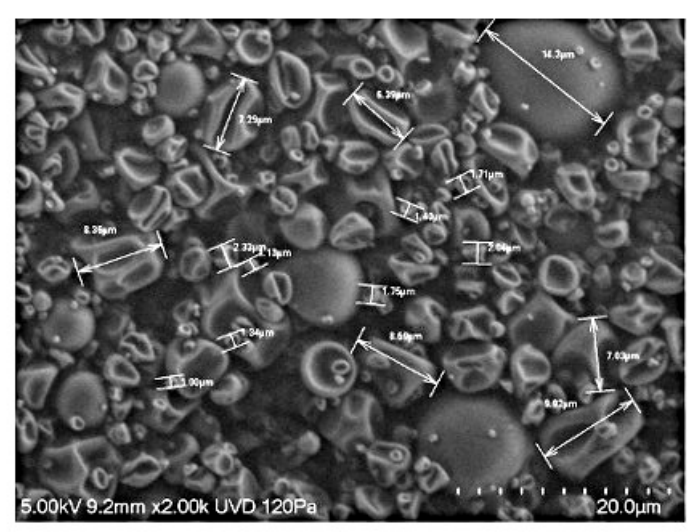

c

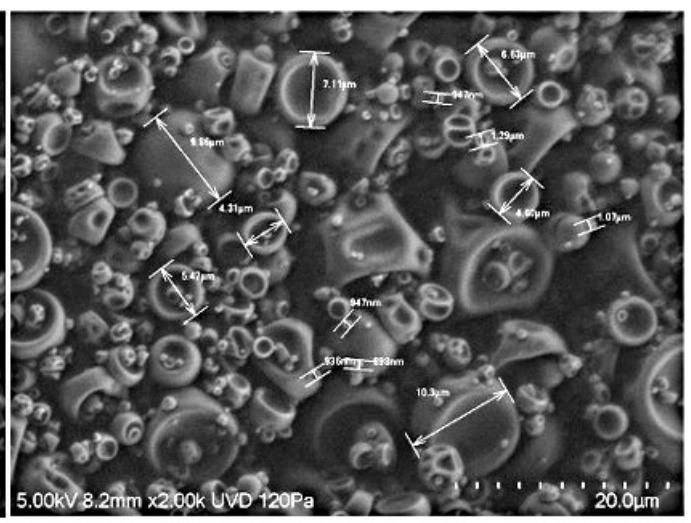

b

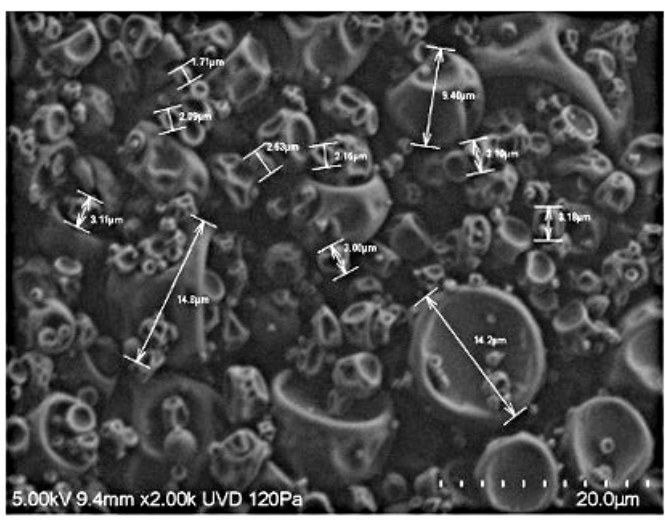

d

Figure 2. SEM images of spray-dried Tintorera grapes extracts at two percentage of maltodextrin and two inlet temperatures. ((a) maltodextrin $10 \%$ and inlet temperature $90{ }^{\circ} \mathrm{C},(\mathbf{b})$. maltodextrin $30 \%$ and inlet temperature $90{ }^{\circ} \mathrm{C},(\mathbf{c})$. maltodextrin $10 \%$ and inlet temperature $120{ }^{\circ} \mathrm{C}$, and (d). maltodextrin $30 \%$ and inlet temperature $120{ }^{\circ} \mathrm{C}$ ).

Table 4. Total Polyphenol contents and antioxidant capacity (ferric reducing antioxidant power (FRAP) and DPPH assays) in Tintorera grapes and their formulations (LT10, LT30, HT10, and HT30).

\begin{tabular}{cccc}
\hline Samples & ${ }^{\mathbf{a}}$ Total Polyphenols & b FRAP & b DPPH \\
\hline Tintorera grapes & $19.77 \mathrm{a}$ & $203.40 \mathrm{a}$ & $108.27 \mathrm{a}$ \\
LT10 & $3.35 \mathrm{~b}$ & $98.62 \mathrm{~b}$ & $39.97 \mathrm{~b}$ \\
LT30 & $2.07 \mathrm{c}$ & $58.12 \mathrm{c}$ & $32.90 \mathrm{c}$ \\
HT10 & $2.76 \mathrm{~b}$ & $120.37 \mathrm{~b}$ & $34.64 \mathrm{c}$ \\
HT30 & $1.93 \mathrm{c}$ & $66.45 \mathrm{c}$ & $31.18 \mathrm{c}$ \\
\hline
\end{tabular}

$\overline{\mathrm{a}}$ Total polyphenols are expressed in gallic equivalent $\left(\mathrm{mg} \mathrm{GAE}^{-1} \mathrm{DW}\right) ;{ }^{\mathrm{b}}$ FRAP and DPPH assay are expressed as $\mu \mathrm{mol}$ Trolox equivalent per gram DW. Different letters within the same column means significant differences at $p<0.05$ in spray-dried powders according to Tukey test. 


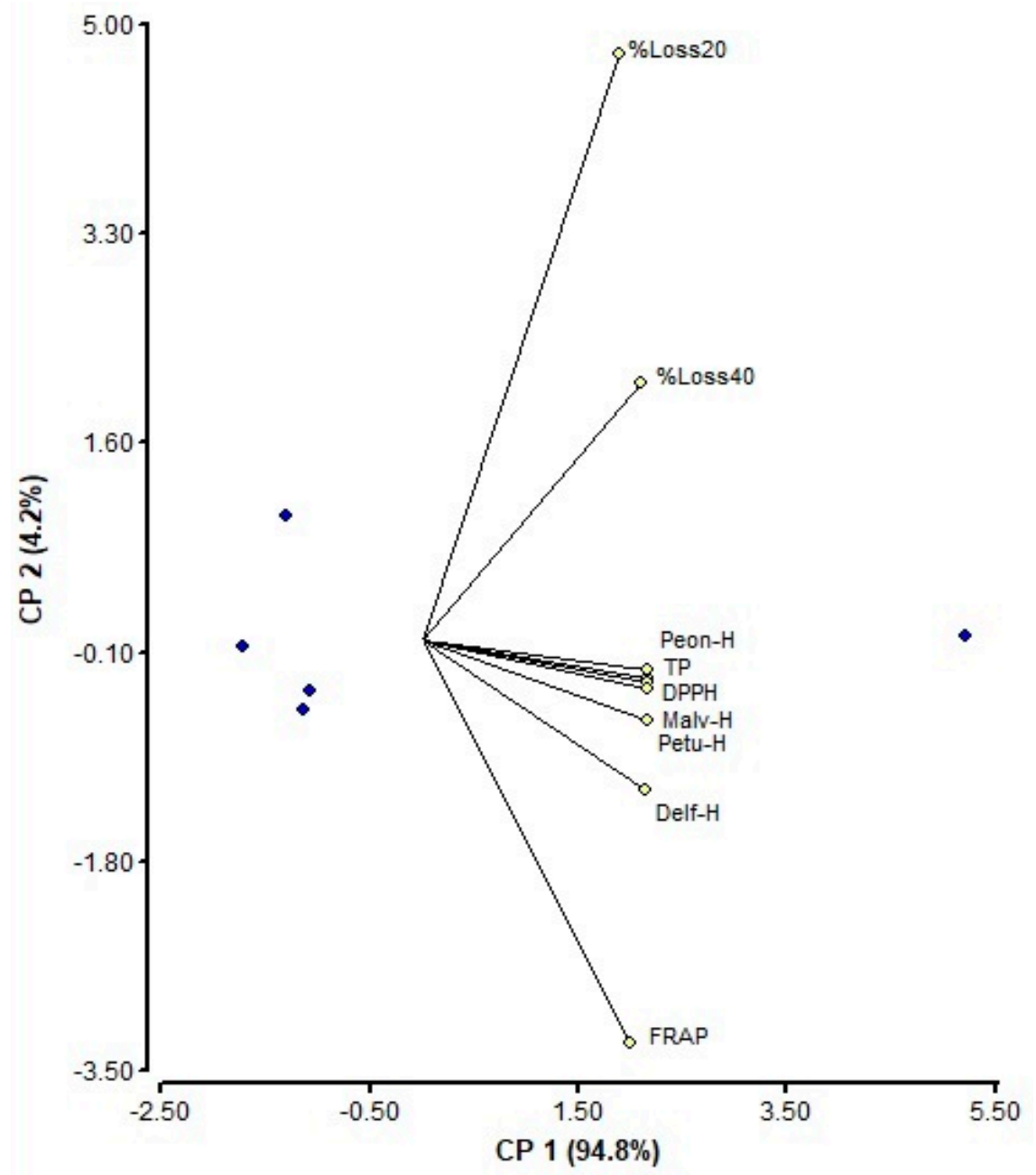

Figure 3. Biplot associated with principal component analysis (PCA) of variables of Tintorera grape formulations. Percentage of losses of malvidin 3-hexoside in formulations maintained at $20{ }^{\circ} \mathrm{C}$ (\%Loss20), percentage of losses of malvidin 3-hexoside in formulations maintained at $40{ }^{\circ} \mathrm{C}$ (\%Loss40), malvidin 3-hexoside content (Malv-H), peonidin 3-hexoside content (Peon-H), petunidin 3-hexoside content (Petu-H), delphinidin 3-hexoside content (Delf-H), total polyphenol contents (TP), DPPH assay (DPPH), and ferric reducing antioxidant power (FRAP) assay (FRAP).

\subsection{Effect of Storage Temperature on Anthocyanin-Rich Formulations of Tintorera Grape}

Changes in the operational conditions were performed, since anthocyanins are sensitive to high temperature. In addition, two storage temperature (20 and $40^{\circ} \mathrm{C}$ for 4 weeks) were used to study degradation of anthocyanins. A study on malvidin 3-hexosides concentration losses in formulations was carried out for 4 weeks, keeping the microspheres at 20 and $40{ }^{\circ} \mathrm{C}$ (Figure 4$)$. 

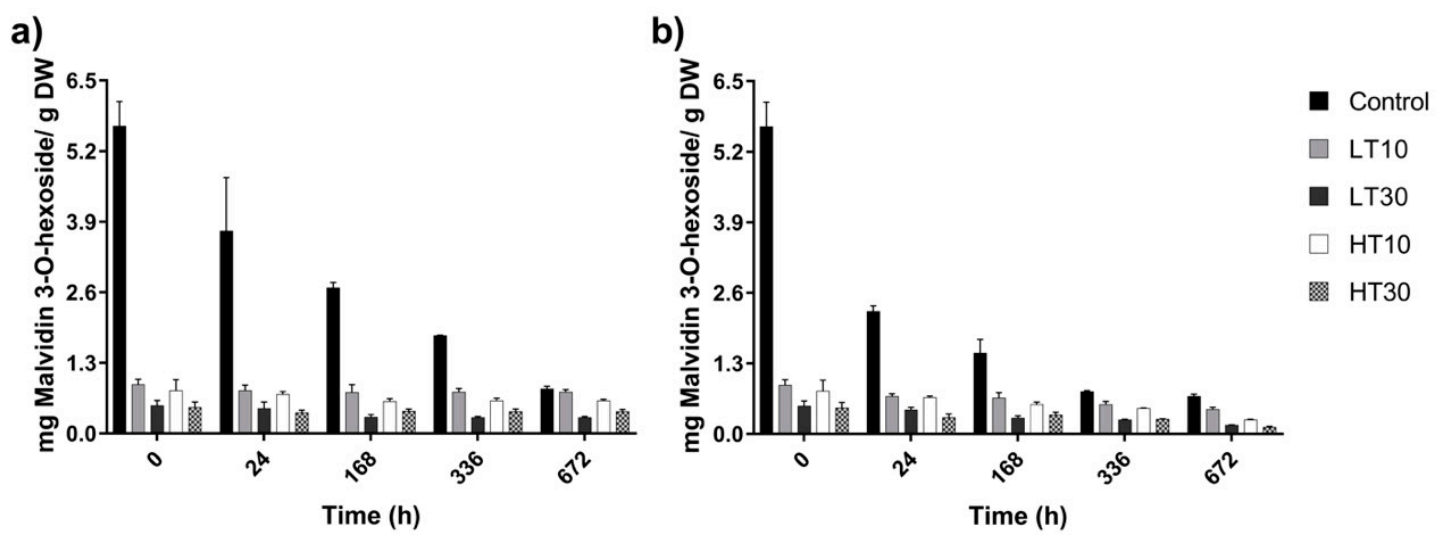

Figure 4. Malvidin 3-hexosides concentration losses in formulations (LT10, LT30, HT10, and HT30) stored at (a) $20{ }^{\circ} \mathrm{C}$ and (b) $40{ }^{\circ} \mathrm{C}$, for $672 \mathrm{~h}$.

Concentrations of malvidin 3-hexoside were higher than in control (without encapsulating), during the 4 weeks of the study at both temperatures, 20 and $40^{\circ} \mathrm{C}$. The losses presented in Tintorera grapes without encapsulating (control) were $86 \%$ at $20{ }^{\circ} \mathrm{C}$ and $88 \%$ at $40{ }^{\circ} \mathrm{C}$. Nonetheless, extracts protected with maltodextrin presented malvidin 3-hexoside losses lesser than $50 \%$ in all treatments at $20^{\circ} \mathrm{C}$ for 4 weeks. However, it did not occur when the formulations were maintained at $40{ }^{\circ} \mathrm{C}$. In this case, the losses were higher, reaching values between $50 \%$ and $75 \%$, but lower when compared with control without protecting. In this assay, also LT10 treatment presented the promising results. Other authors [11] demonstrated that the storage of spray-dried formulated grape extracts improved the stability of anthocyanins over time, although their studies are mainly based on changes in humidity.

Finally, a Biplot associated with principal component analysis (PCA) of variables of Tintorera grape formulations is presented (Figure 3).

PCA was employed by mean centered data based on the eigen values to determine the correlation between variables and the discrimination of anthocyanin contents of Tintorera formulations and antioxidant characteristics in different conditions of temperature of the process and storage temperature. The variables used were percentage of losses of malvidin 3-hexoside in formulations maintained at $20^{\circ} \mathrm{C}$ (\%Loss20), percentage of losses of malvidin 3-hexoside in formulations maintained at $40{ }^{\circ} \mathrm{C}$ (\%Loss40), malvidin 3-hexoside content (Malv-H), peonidin 3-hexoside content (Peon-H), petunidin 3-hexoside content (Petu-H), delphinidin 3-hexoside content (Delf-H), total polyphenol contents (TP), DPPH assay (DPPH), and FRAP assay (FRAP).

The correlation between the variables was high and statistically significant. A positive linear relationship was found between the variables. First, the selection criterion of eigen values greater than 1 was used. However, it was observed that the second component explained more fully the variability observed in relation to the FRAP assay and the percentages of loss of malvidin 3-hexoside at temperatures storage of 20 and $40^{\circ} \mathrm{C}$. From the Biplot, a simultaneously visualization of observations and variables are presented. Hence, it can be seen that the individual anthocyanin content in the different spray-drying treatments as well as the total polyphenol content and the DPPH antioxidant capacity assays showed a projection to the right of $\mathrm{CP} 1$, while the FRAP assay and the loss percentages malvidin 3-hexoside at storage temperatures of 20 and $40{ }^{\circ} \mathrm{C}$ would be represented by both components. Therefore, the variables mentioned above that are projected to the right would be the ones that would be most affected by the different thermal treatments that were performed through spray-drying.

\section{Conclusions}

Tintorera grape (Vitis vinifera) was studied due to its promising nutritional value in view of managing the overproduction of this grape that is used mainly for wine coloring. 
Tintorera grapes exhibited high anthocyanin contents and corresponding high antioxidant capacity, as well as potential as inhibitors of enzymes involved in the pathological conditions of energy metabolism (lipase and $\alpha$-glucosidase) as well as inflammatory and cognitive decline problems (acetylcholinesterase). The encapsulation offers protection to the anthocyanins of Tintorera grapes, combined with adding maltodextrin $(10 \%$ w:v) and reductions of the incident light and the inlet temperature. Considering the lack of current uses for the agrowaste of the wine-making industry delivering tons of Tintorera grape waste annually, the valorization into functional ingredients offer an innovative waste recovery strategy.

Supplementary Materials: The following are available online at https://www.mdpi.com/2227-971 7/9/3/518/s1, Table S1: Identification and quantification ( $\left.\mathrm{mg} \mathrm{g}^{-1} \mathrm{DW}\right)$ of phenolic compounds in formulations (LT10, LT30, HT10 and HT30) by HPLC-DAD-ESI/MS.

Author Contributions: M.D.L.-B.: conceptualization, writing-original draft, and funding acquisition, E.F.C.: methodology, formal analysis, and writing, G.P.: writing and formal analysis, F.N.: formal analysis, data curing, and editing, P.F.-M.: methodology, M.E.R.-R.: writing-reviewing and editing, P.J.: methodology, M.S.: methodology and writing_-reviewing and editing, I.S.: reviewing and editing, D.A.M.: methodology and reviewing and editing. All authors have read and agreed to the published version of the manuscript.

Funding: This work has been supported by the FONDECYT grant 1160899 (CONICYT, Chile).

Institutional Review Board Statement: Not applicable.

Informed Consent Statement: Not applicable.

Data Availability Statement: Not applicable.

Acknowledgments: Recognition and gratitude to the technicians of Chemical Analysis Laboratory, Department of Plant Production-University of Concepción, Chillán.

Conflicts of Interest: The authors declare no conflict of interest.

\section{References}

1. Salehi, B.; Sharifi-Rad, J.; Herrera-Bravo, J.; Salazar, L.A.; Delporte, C.; Barra, G.V.; Cazar Ramirez, M.E.; Lopez, M.D.; Ramirez Alarcon, K.; Martins, N.; et al. Ethnopharmacology, Phytochemistry and Biological Activities of Native Chilean Plants. Curr. Pharm. Des. 2020, 26, 1-23. [CrossRef]

2. Aizpurua-Olaizola, O.; Ormazabal, M.; Vallejo, A.; Olivares, M.; Navarro, P.; Etxebarria, N.; Usobiaga, A. Optimization of supercritical fluid consecutive extractions of fatty acids and polyphenols from Vitis vinifera grape wastes. J. Food Sci. 2015, 80, E101-E107. [CrossRef] [PubMed]

3. Maicas, S.; Mateo, J.J. Sustainability of Wine Production. Sustainability 2020, 12, 559. [CrossRef]

4. Fontana, A.R.; Antoniolli, A.; Bottini, R. Grape pomace as a sustainable source of bioactive compounds: Extraction, characterization, and biotechnological applications of phenolics. J. Agric. Food Chem. 2013, 61, 8987-9003. [CrossRef]

5. Castillo-Munoz, N.; Fernandez-Gonzalez, M.; Gomez-Alonso, S.; Garcia-Romero, E.; Hermosin-Gutierrez, I. Red-color related phenolic composition of Garnacha Tintorera (Vitis vinifera L.) grapes and red wines. J. Agric. Food Chem. 2009, 57, 7883-7891. [CrossRef]

6. Castillo-Munoz, N.; Gomez-Alonso, S.; Garcia-Romero, E.; Hermosin-Gutierrez, I. Flavonol profiles of Vitis vinifera red grapes and their single-cultivar wines. J. Agric. Food Chem. 2007, 55, 992-1002. [CrossRef] [PubMed]

7. Zhu, L.; Zhang, Y.; Lu, J. Phenolic contents and compositions in skins of red wine grape cultivars among various genetic backgrounds and originations. Int. J. Mol. Sci 2012, 13, 3492-3510. [CrossRef] [PubMed]

8. Rondeau, P.; Gambier, F.; Jolibert, F.; Brosse, N. Compositions and chemical variability of grape pomaces from French vineyard. Ind. Crop. Prod. 2013, 43, 251-254. [CrossRef]

9. Anandharamakrishnan, C. Spray Drying Techniques for Food Ingredient Encapsulation; Wiley: Hoboken, NJ, USA, 2015.

10. Gharsallaoui, A.; Roudaut, G.; Chambin, O.; Voilley, A.; Saurel, R. Applications of spray-drying in microencapsulation of food ingredients: An overview. Food Res. Int. 2007, 40, 1107-1121. [CrossRef]

11. Tolun, A.; Artik, N.; Altintas, Z. Effect of different microencapsulating materials and relative humidities on storage stability of microencapsulated grape pomace extract. Food Chem. 2020, 302, 125347. [CrossRef] [PubMed]

12. Moreno, T.; Cocero, M.J.; Rodríguez-Rojo, S. Storage stability and simulated gastrointestinal release of spray dried grape marc phenolics. Food Bioprod. Process. 2018, 112, 96-107. [CrossRef] 
13. Souza, V.B.; Fujita, A.; Thomazini, M.; Da Silva, E.R.; Lucon, J.F., Jr.; Genovese, M.I.; Favaro-Trindade, C.S. Functional properties and stability of spray-dried pigments from Bordo grape (Vitis labrusca) winemaking pomace. Food Chem. 2014, 164, 380-386. [CrossRef] [PubMed]

14. Gironés-Vilaplana, A.; Baenas, N.; Villaño, D.; Speisky, H.; García-Viguera, C.; Moreno, D.A. Evaluation of Latin-American fruits rich in phytochemicals with biological effects. J. Funct. Foods 2014, 7, 599-608. [CrossRef]

15. Noriega, F.; Mardones, C.; Fischer, S.; García-Viguera, C.; Moreno, D.A.; López, M.D. Seasonal changes in white strawberry: Effect on aroma, phenolic compounds and its biological activity. J. Berry Res. 2020, 11, 103-118. [CrossRef]

16. Gilham, D.; Lehner, R. Techniques to measure lipase and esterase activity in vitro. Methods 2005, 36, 139-147. [CrossRef]

17. Ellman, G.L.; Courtney, K.D.; Andres, V., Jr.; Feather-Stone, R.M. A new and rapid colorimetric determination of acetylcholinesterase activity. Biochem. Pharmacol. 1961, 7, 88-95. [CrossRef]

18. Chan, H.-H.; Sun, H.-D.; Reddy, M.V.B.; Wu, T.-S. Potent $\alpha$-glucosidase inhibitors from the roots of Panax japonicus CA Meyer var. major. Phytochemistry 2010, 71, 1360-1364. [CrossRef] [PubMed]

19. Singleton, V.L.; Rossi, J.A. Colorimetry of total phenolics with phosphomolybdic-phosphotungstic acid reagents. Am. J. Enol. Vitic. 1965, 16, 144-158.

20. Mena, P.; García-Viguera, C.; Navarro-Rico, J.; Moreno, D.A.; Bartual, J.; Saura, D.; Martí, N. Phytochemical characterisation for industrial use of pomegranate (Punica granatum L.) cultivars grown in Spain. J. Sci. Food Agric. 2011, 91, 1893-1906. [CrossRef] [PubMed]

21. López, M.D.; Baenas, N.; Retamal-Salgado, J.; Zapata, N.; Moreno, D.A. Underutilized Native Biobío Berries: Opportunities for Foods and Trade. Nat. Prod. Commun. 2018, 13, 1934578X1801301226. [CrossRef]

22. Makris, D.P.; Kallithraka, S.; Kefalas, P. Flavonols in grapes, grape products and wines: Burden, profile and influential parameters. J. Food Compos. Anal. 2006, 19, 396-404. [CrossRef]

23. Figueiredo-Gonzalez, M.; Cancho-Grande, B.; Simal-Gandara, J. Evolution of colour and phenolic compounds during Garnacha Tintorera grape raisining. Food Chem. 2013, 141, 3230-3240. [CrossRef]

24. Figueiredo-Gonzalez, M.; Regueiro, J.; Cancho-Grande, B.; Simal-Gandara, J. Garnacha Tintorera-based sweet wines: Detailed phenolic composition by HPLC/DAD-ESI/MS analysis. Food Chem. 2014, 143, 282-292. [CrossRef] [PubMed]

25. De Torres, C.; Diaz-Maroto, M.C.; Hermosin-Gutierrez, I.; Perez-Coello, M.S. Effect of freeze-drying and oven-drying on volatiles and phenolics composition of grape skin. Anal. Chim. Acta 2010, 660, 177-182. [CrossRef] [PubMed]

26. Gomaa, A.A.; El-Sers, D.A.; Al-Zokeim, N.I.; Gomaa, M.A. Amelioration of experimental metabolic syndrome induced in rats by orlistat and Corchorus olitorius leaf extract; role of adipo/cytokines. J. Pharm. Pharmacol. 2019, 71, 281-291. [CrossRef] [PubMed]

27. Ogura, H.; Kosasa, T.; Kuriya, Y.; Yamanishi, Y. Comparison of inhibitory activities of donepezil and other cholinesterase inhibitors on acetylcholinesterase and butyrylcholinesterase in vitro. Methods Find. Exp. Clin. Pharmacol. 2000, 22, 609-613. [CrossRef]

28. Önal, S.; Timur, S.; Okutucu, B.; Zihnioğlu, F. Inhibition of $\alpha$-glucosidase by aqueous extracts of some potent antidiabetic medicinal herbs. Prep. Biochem. Biotechnol. 2005, 35, 29-36. [CrossRef]

29. Pintac, D.; Cetojevic-Simin, D.; Berezni, S.; Orcic, D.; Mimica-Dukic, N.; Lesjak, M. Investigation of the chemical composition and biological activity of edible grapevine (Vitis vinifera L.) leaf varieties. Food Chem. 2019, 286, 686-695. [CrossRef]

30. Céspedes, C.L.; El-Hafidi, M.; Pavon, N.; Alarcon, J. Antioxidant and cardioprotective activities of phenolic extracts from fruits of Chilean blackberry Aristotelia chilensis (Elaeocarpaceae), Maqui. Food Chem. 2008, 107, 820-829. [CrossRef]

31. Wang, H.; Guo, X.; Hu, X.; Li, T.; Fu, X.; Liu, R.H. Comparison of phytochemical profiles, antioxidant and cellular antioxidant activities of different varieties of blueberry (Vaccinium spp.). Food Chem. 2017, 217, 773-781. [CrossRef] 